\title{
MENAFSIRKAN MITOS SEBAGAI MEDIA MITIGASI BENCANA DI MASYARAKAT SUNDA
}

\section{Interpreting Myths As A Medium of Disaster Mitigation in Sunda Community}

\author{
Yeni Mulyani Supriatin \\ Balai Bahasa Provinsi Jawa Barat \\ Jalan Sumbawa Nomor 11, Bandung 40113 \\ E-mail: yeni.mulyani1512@gmail.com
}

\begin{abstract}
This paper is based on the background of the myth of Simeuleu in Aceh which states that if an earthquake occurs, you must immediately find a high place to avoid a tsunami. When the 2004 earthquake hit Aceh, the number of tsunami victims in Simeuleu tended to be few because the community could interpret and take advantage of Simeuleu's myths. This study aims to interpret Sundanese myths relating to human safety so that they can be used as a medium for disaster mitigation. The problem of this research is how to interpret Sundanese myths as disaster mitigation media? The approach used is a modern approach by applying the participation extension technique, observation persistence, triangulation, and peer checking. The results of the study found myths that can be used as disaster mitigation media. This research concludes that the Sundanese myth of a kind of smong can be used as a medium for disaster mitigation.
\end{abstract}

Keyword: myth, mitigation, modern approaches

\begin{abstract}
Abstrak
Makalah ini dilatarbelakangi smong sebuah mitos Simeuleu di Aceh yang menyebutkan jika terjadi gempa harus segera mencari tempat tinggi untuk menghindari tsunami. Ketika tahun 2004 gempa melanda Aceh, korban tsunami di Simeuleu cenderung sedikit karena masyarakat dapat menafsirkan dan memanfaatkan mitos Simeuleu. Penelitian ini bertujuan menafsirkan mitos-mitos Sunda yang berkaitan dengan keselamatan umat manusia agar dapat dimanfaatkan sebagai media mitigasi bencana. Masalah penelitian ini adalah bagaimana menafsirkan mitosmitos Sunda sebagai media mitigasi bencana? Pendekatan yang digunakan adalah pendekatan modern dengan menerapkan teknik perpanjangan keikutsertaan, ketekunan pengamatan, triangulasi, dan pengecekan rekan sejawat. Hasil penelitian ditemukan mitos-mitos yang dapat dimanfaatkan sebagai media mitigasi bencana. Simpulan penelitian ini adalah bahwa mitos Sunda sejenis smong dapat dimanfaatkan sebagai media mitigasi bencana.
\end{abstract}

Kata kunci: mitos, mitigasi, pendekatan modern

\section{PENDAHULUAN}

Semenjak bencana alam tsunami yang memakan ratusan ribu korban di Aceh pada 26 Desember2004, Pulau Simeulue menjadi menarik perhatian. Simeulue adalah pulau terdekat dengan episentrum gempa daripada Banda Aceh. Jika diilustrasikan, tsunami datang di Banda Aceh sekitar 20-30 menit setelah gempa, tetapi ke Pulau Simeulue sekitar 10 menit. Namun, menarik dan menakjubkan di pulau itu nyaris tidak ada korban jiwa. Yang tercatat kurang dari 10 orang korban jiwa tepatnya 7 orang. Orang bertanya-tanya hal apa yang menyebabkan warga Pulau Simeuleu lolos dari bencana dasyat itu. Para investigasi bencana menemukan smong di Simeulue sebuah dongeng yang kemudian menjadi mitos yang diturunkan secara lisan. Smong merupakan pengetahuan lokal terkait bencana tsunami. Smong berhasil menjadi sirene peringatan 
yang terus direproduksi sehingga saat tsunami datang dapat meminimalkan korban, demikian menurut Indrajaya (2020).

Sementara itu, di Pangandaran pada tahun 2005 beberapa warga sekitar justru tidak memahami fenomena alam terkait gempa dan tsunami. Saat air laut surut tiba-tiba, warga yang bermatapencaharian mencari rumput laut justru berlarian ke laut dan memungutinya, Ketika gelombang laut datang, mereka tidak sempat menyelamatkan diri.

Peristiwa tsunami di Simeulue dan Pangandaran memperkuat hipotesis kebermanfaatan mitos (sastra) untuk pengetahuan lokal yang dapat digunakan sebagai media mitigasi bencana. Mitos yang berkaitan dengan bencana sejenis smong dalam tradisi lisan Sunda sangat penting ditafsirkan dan dipublikasikan sebagai media mitigasi bencana untuk meminimalkan korban jiwa. Yang menjadi masalah dalam penelitian ini adalah mitos seperti apa dan bagaimana menafsirkan mitos tersebut sehingga dapat bermanfaat sebagai media mitigasi bencana.

Penelitian yang berkaitan dengan bencana (alam) atau yang disebabkan oleh manusia bukan hal baru dalam kajian sastra. Mahayana (2007) menyampaikan bahwa persoalan alam dan lingkungannya sebenarnya telah lama digaungkan oleh para sastrawan. Karya sastra pada hakikatnya selalu memiliki keterkaitan dengan lingkungannya meskipun ia dikemas dan disampaikan dalam kerangka yang imajinatif. Keterkaitan tersebut bisa dengan lingkungan sosial, budaya, politik, dan alam.

Kajian-kajian sastra yang mempersoalkan hubungan antara karya sastra dengan lingkungan alam, dengan lingkungan fisik, pertumbuhan populasi, hilangnya hutan belantara dan liar, punahnya spesies dengan cepat, serta peningkatan kontaminasi udara, air, dan tanah di bumi telah dilakukan oleh Wijanarti (2019), Anafiah (2014), dan Supriatin (2010). Wijanarti menggambarkan masyarakat Dayak di Kalimantan Tengah yang berupaya menjaga lingkungan alam agar tidak terjadi bencana. Kemudian, Anafiah menggambarkan struktur komik yang berkaitan dengan mitigasi bencana dan Supriatin menggambarkan bagaimana masyarakat Darmaraja memanfaatkan mitos mereka untuk menentang pembangunan waduk Jatigede yang diperkirakan akan mendatangkan bencana seperti banjir dan hilangnya tinggalan budaya mereka.

Penelitian tentang mitos Sunda yang mengaitkan dengan mitigasi bencana yang dilakukan sekarang belum ada yang mengkajinya. Penelitian ini penting untuk menambah pengetahuan masyarakat apabila menghadapi bencana alam yang datangnya tidak dapat diduga. Di samping itu setidaknya dapat mengurangi risiko/dampak bencana alam, termasuk korban jiwa, kerugian harta benda, dan kerusakan lingkungan.

Secara teoritis penelitian ini memanfaatkan teori mitos. Holman dalam Zaidan ( 1997) menegaskan bahwa setiap kesusastraan memiliki mitologinya. Holman juga menyebutkan arti mite, yaitu sebagai cerita anonim yang menyajikan episode adikodrati sebagai cara menafsirkan kejadian alam. Dalam arti seperti itu mite berfungsi mengonkretkan persepsi manusia yang khas. Zaidan dalam kajiannya tentang berbagai makna mite tiba pada simpulan bahwa pikiran mistis (yang bersumber dari mite) telah menjadi bentuk pikiran yang lazim untuk saat ini dan masa yang akan datang. 
Sesungguhnya, dalam kehidupan sehari-hari, manusia sebagai makhluk sosial memerlukan pengendali tindakan, yang salah satu wujudnya adalah mitologi itu.

Sementara itu, Ruthven (1997) menyoroti mitos yang terdapat dalam puisi. Menurutnya bahwa dalam setiap karya sastra pemikiran yang bersumber dari mite merupakan keniscayaan. Ia menganggap mite sebagai sesuatu yang mengandung proyeksi pola-pola sosial ke atas tataran manusia yang unggul yang mengandung sanksi dan mengukuhkan ideologi.

Pemahaman mite lebih jelas terdapat pada konsep Day dalam Zaidan (1997) yang mengelompokkan mite dalam empat tataran. Keempat tataran mite itu adalah mite kunaan sebagai tataran pertama yang tumbuh dan hidup dalam masyarakat primitif. Tataran mite kedua adalah mite antaraan (intermediate myth) yang dibentuk oleh pengarang dengan keahlian kesadaran yang penuh. Tataran mite ketiga adalah mite turunan yang dikembangkan lebih lanjut dari mite antaraan. Terakhir, mite ideologis adalah mite yang diciptakan manusia modern yang banyak menjadi sasaran penelitian psikologi. Dalam kaitannya dengan mite ideologis.

Mite atau mitos dalam teori sastra bagian dari tradisi lisan yang dimaknai sebagai materi kebudayaan dan tradisi yang diwariskan secara lisan dari satu generasi ke generasi lainnya. Menurut Vansina (1985) tradisi lisan adalah pesan verbal, pernyataan yang disampaikan dari generasi ke genearasi berupa yang dinyanyikan menggunakan alat musik atau dituturkan atau pertunjukan yang mengandung transmisi verbal dan nonverbal.

Pudentia (2016) menegaskan bahwa yang termasuk tradisi lisan tidak hanya folklore, cerita-cerita, tetapi juga berbagai hal yang menyangkut sistem pengetahuan lokal, sistem geneologi, sejarah, hokum, lingkungan, alam semesta, adat istiadat, tekstil, obat-obatan, dan kepercayaan, bahasa, serta seni. Dengan demikian, mitos Sunda yang berkaitan dengan mitigasi bencana termasuk tradisi lisan yang disampaikan secara turun-temurun.

Penelitian ini berkaitan dengan mitigasi bencana sehingga konsep tentang mitigasi juga perlu dikemukakan. Mitigasi bencana didefinisikan sebagai upaya yang ditujukan untuk mengurangi dampak dari bencana, baik bencana alam, bencana ulah manusia maupun bencana gabungan dari keduanya dalam suatu negara atau masyarakat Permendagri (2006) diunduh pada tanggal 28 Oktober 2020. Mitigasi merupakan bagian dari manajemen penanganan bencana, menjadi salah satu tugas Pemerintah Pusat dan Pemerintah Daerah dalam rangka pernberian rasa aman dan pelindungan dari ancaman bencana yang mungkin akan terjadi.

Metode penelitian dalam pengumpulan dan penganalisisan data menggunakan pendekatan modern yang dikemukakan oleh Danandjaja dalam Pudentia (2019) yang memperhatikan aspek folk dan lore dari tradisi lisan yang dikaji. Pendekatan modern lebih bersifat holistik dalam arti waktu melakukan pengkajian akan dikaitkan dengan latar belakang atau konteks kebudayaan tradisi lisan tersebut sehingga hasil kajiannya bersifat emik, yakni melihat dari sudut folk yang menjadi objek kajian tradisi lisan. 
Selanjutnya, untuk pengecekan keabsahan data akan dilakukan beberapa teknik berikut ini.

Pertama, perpanjangan keikutsertaan. Sebagai orang yang ikut dalam merancang dan melakukan instrumen penelitian, dalam penelitian kualitatif, keikutsertaan peneliti sangat menentukan dalam pengumpulan data. Kedua, ketekunan pengamatan. Teknik ini bertujuan untuk menemukan ciri-ciri dan unsur-unsur dalam situasi yang sangat relevan dengan persoalan atau isu yang sedang dicari. Ketiga, triangulasi. Teknik ini bertujuan memeriksa keabsahan data dengan memanfaatkan sesuatu yang lain di luar data untuk keperluan pengecekan atau sebagai pembanding terhadap data itu. Dalam penelitian ini trianggulasi dilakukan dengan mengecek balik suatu informasi atau data pada sumber data dengan metode yang sama dan dalam waktu yang berbeda. Keempat, pengecekan rekan sejawat. Teknik ini dilakukan dengan mengekspos hasil sementara atau hasil akhir kepada teman sejawat dalam bentuk diskusi analitik. Teknik ini bertujuan agar peneliti mempertahankan sikap terbuka dan kejujuran.

\section{PEMBAHASAN}

\section{Mitos Darmaraja Media Mitigasi Bencana}

Darmawan atau lebih dikenal dengan sapaan Ki Wangsa, informan penelitian, menerangkan bahwa masyarakat Darmaraja memiliki mitos yang disebut Babon Darmaraja dan mitos keuyeup bodas. Mitos tersebut sangat melekat dan mengakar dalam hati sanubari masyarakat Sumedang. Mitos itu menyebutkan bahwa suatu saat Sungai Cimanuk yang bermata air di Garut akan dibendung dan sebagian kawasan Sumedang akan digenangi air. Sawah dan ladang disulap menjadi sebuah telaga yang besar. Babon Darmaraja itu dapat dipahami setelah di kawasan Sumedang tepatnya di Jatigede dibangun Waduk Jatigede.

Meskipun sudah terwujud, keberadaan Waduk Jatigede menurut mitos Darmaraja dan mitos keuyeup bodas tetap mengancam jiwa manusia, sebagaimana terbaca dalam kutipan berikut.

Jatigede dikeueum bakal ngahudangkeun keuyeup bodas anu bakal ngobobol bendungan, Cipelang Cikamayangan, Bandung Heurin ku Tangtung, Sumedang Ngarangrangan, Kadipaten kapapatenan, Tomo totolomoan, Cirebon kabongbodasan.

Intinya: Jatigede apabila digenangi air akan membangunkan kepiting putih yang akan menjebol bendungan. Kepiting umumnya berwana gelap, tetapi dalam mitos ini kepiting berwarna putih. Dengan demikian, kepiting putih adalah metafor yang secara metaforis dapat ditafsirkan sebagai sesar (rekahan pergeseran) beribis, Lembang dan Cimandiri yang nyambung dan membentuk lengkung seperti kepiting. Jika sesar aktif ini bergerak, bendungan bisa jebol dan rusak. Bukan hanya Sumedang, melainkan daerah lain di sekitarnya seperti Bandung, Tomo, Kadipaten, dan Cirebon akan terkena bencana gempa bahkan terjadi tsunami.

Mitos Darmaraja dan keuyeup bodas tersebut dapat ditafsirkan mengandung bencana yang akan terjadi pada suatu saat kelak berupa bencana alam dan bencana karena ulah manusia. Sementara itu, mitos lainnya seperti mitos Resi Aji Putih dan 
Wangsit Siliwangi sebagai leluhur mereka memberi ilmu pengetahuan lokal untuk menghindari bencana jika benar-benar terjadi. Hal itu dipandang sebagai mitigasi bencana yang dapat dilakukan sebelum terjadi bencana. Mitigasi bencana tersebut terbaca dalam kutipan berikut.

"Ulah sina talangké, sabab talaga bakal bedah! Dia nu di beulah kulon! Papay ku dia lacak Ki Santang! Sabab engkéna, turunan dia jadi panggeuing ka dulur jeung ka batur. Ka batur urut salembur, ka dulur anu nyorang saayunan ka sakabéh nu rancagé di haténa. Engké jaga, mun tengah peuting, ti gunung Halimun kadéngé sora tutunggulan, tah éta tandana; saturunan dia disambat ku nu dék kawin di Lebak Cawéné. Ulah sina talangké, sabab talaga bakal bedah! Jig geura narindak! Tapi ulah ngalieuk ka tukang!"

Jangan lengah! Telaga bakal meluap. Hai yang di barat! Carilah Ki Santang! Karena kelak turunan dia yang akan mengingatkan saudaranya dan orang lain. Teman sekampung, pada keluarga yang rukun, seia-sekata dan semua orang yang baik hatinya. kelak, apabila tengah malam, dari gunung Halimun terdengar suara lesung dan alu yang terus-menerus, itu adalah suatu pertanda. Semua turunan kalian dipanggil oleh yang akan menikah di Lebak Cawéné. Jangan lengah, waspadalah sebab telaga akan jebol! Segera pergi, tinggalkan tempat itu ! Ingat! Jangan menoleh ke belakang!

Tema dalam mitos Darmaraja,Keuyeup Bodas, Aji Putih, dan Wangsit Siliwangi tersebut adalah tentang bencana yang setiap saat mengancam, mitigasi bencana yang dapat dilakukan sebelum terjadi bencana, dan pascabencana jika bencana itu terjadi.

\section{Mitos Nyi Pohaci Sanghyang Sri sebagai Prasyarat Keselamatan}

Fakta bahwa Jawa Barat merupakan negeri agraris tidak hanya dilihat dari pentingnya sektor pertanian sebagai penopang perekonomian penduduknya, tatapi lebih jauh dapat dilihat pula budaya dan ritual-ritual yang dilakukannya. Fenomena itu teraktualisasikan di Sinar Resmi dan Ciptagelar. Keduanya adalah sebuah permukiman adat Sunda berbasis budaya padi. Keduanya adalah lembur atau Kampung Gede dan pusat kasepuhan bagi tari kolot (kasepuhan lama) yang terikat secara adat dan budaya. Kasepuhan itu merupakan kesatuan adat Banten Kidul.

Kusdiwanggo \& Sumardjo (2016) menerangkan bahwa pola kehidupan masyarakat Ciptagelar menjalankan ajaran dan tradisi nenek moyang karuhun yang berasaskan pada budaya padi. Masyarakat budaya padi adalah masyarakat yang memiliki seperangkat nilai dan kepercayaan supernatural terhadap entitas padi. Kepercayaan tersebut masih tetap bertahan dan terus berkembang sampai dengan sekarang. Kepercayaan pada entitas padi terpatri dalam tatanilai, tatapikir, tatalaku ritual dalam wujud pertanian. Kegiatan pertanian terhubung dengan ritual kesakralan dan mitos yang setidaknya terdapat 32 rangkaian ritual budaya padi selama satu siklus masa tanam. Berikut beberapa ritual budaya padi sebagai prasyarat keselamatan.

\section{(1) Peredaran Bintang}

Pengamatan peredaran bintang dimanfaatkan untuk pertanian. Masyarakat kasepuhan melihat peredaran bintang di langit. Hal itu mengacu pada kosep Bapak 
langit yang menunjukkan adanya pengetahuan lokal yang didasarkan pada kejadian di alam sebagai acuan mengolah lahan garapan. Konsep lain adalah guru mangsa artinya berguru pada alam dalam hal waktu untuk melakukan kegiatan. Tatalaku itu merupakan tradisi adat Banten Kidul sebagaimana disampaikan Hermawan (2012) bahwa masyarakat Baduy di Banten Selatan menentukan waktu untuk pertanian di huma dan sawah berpatokan pada peredaran bintang di langit. Ngahuma sataun sakali nyokot anggeuran ka bentang 'berladang setahun sekali mengambil patokan pada bintang'. Bintang yang menjadi patokan perhitungan pertanian adalah Kidang (Wuluku atau Orion) dan bintang Kartika (Kerti).

Tanggal kerti kana beusi, tanggal kidang turun kujang, artinya masyarakat sudah harus mempersiapkan alat-alat pertanian seperti sabit, pacul, garpu dan sebagainya.

Kidang ngarangsang ti wetan, Kerti ngarangsang ti Kulon atau Kidang-Kerti pahareup-hareup. Tanda musim panas serta waktu untuk membakar ranting dan daun di huma (ngahuru).

Kerti mudun matang mencrang di tengah langit, saat ngaseuk (menanam padi di huma) sudah tiba.

Kidang medang turun kungkang. Artinya tanda akan ada hama dan penyakit yang dapat menyerang tanaman padi.

Kidang dan kerti ka kulon, yang berarti musim hujan akan tiba

Dengan panduan rasi bintang di langit, yakni saat rasi bintang kidang mulai condong ke Barat, penanaman padi dapat dimulai. Pengetahuan lokal ini mampu menghindari serangan hama padi karena pada saat bintang kidang mulai terbenam yang dalam istilah Sunda disebut dengan tilem kidang turun kungkang hama padi mulai bermunculan sehingga tanaman harus sudah dipanen.

Peredaran bintang Kidang dan Kerti di langit dipandang sebagai latar dalam aktivitas penanaman padi yang dapat digunakan sebagai bagian mitigasi bencana. Disebut mitigasi bencana karena jika gagal panen akibat kekeringan atau padi kena kungkang 'hama wereng' mengakibatkan bencana kelaparan atau kemiskinan. Dengan demikian, meneliti peredaran bintang yang berkaitan dengan waktu penanaman padi dipandang sebagai upaya pencegahan bencana.

(2) Padi adalah Ibu

Mitigasi bencana dengan cara memperlakukan padi sebagaimana Ibu juga terungkap pada saat pare nyiram (saat padi mulai berbunga). Pada ritual tersebut padi dimetaforkan dengan perempuan yang mengadung 7 bulan. Ibu-ibu menyediakan rujak terbuat dari 7 macam buah, bubur merah bubur putih, dan juga membacakan doa-doa keselamatan dan Surat Yusuf dan Mariam. Tujuannya tiada lain agar padi yang mulai berbuah selamat sampai panen dan menghasilkan biji padi yang melimpah.

Mitigasi bencana juga terekspresikan dalam aktivitas masyarakat kasepuhan pada saat pascapanen. Dari sekian banyak rangkaian ritual budaya padi tersebut terdapat satu ritual sebagai salah satu asas kehidupan di Ciptagelar, yaitu ngadiukkeun pare 'mendudukkan padi ke dalam lumbung'. Upacara ngadiukkeun adalah upacara memasukkan atau mendudukkan padi ke dalam lumbung. Ngadiukkeun pare 
memberikan pengetahuan kepada warga bagaimana cara hidup berhemat sehingga jika bencana datang mereka siap menghadapinya.

Lumbung keramat tempat menyimpan padi sebagai bekal jika musibah menimpa. Lumbung ini juga diperuntukkan semua warga kasepuhan yang kekurangan bekal. Lumbung padi kasepuhan dalam istilah Sumarjo (2009) disebut sebagai bank genetik. Padi yang disimpan dalam lumbung tidak dipisahkan dari tangkainya, bergantung pada tali bambu (pocongan). Pocongan disimpan pada galah bambu menggunakan batang kayu. Dengan cara ini padi tetap mengering dan memiliki kadar air yang tidak berubah. Pocongan padi disimpan dalam leuit yang berbentuk unik, berpintu satu, dan beratap rumbia. Rancangan ini mampu menahan bocor dan menutup jalan tikus.

Sebagai prasyarat keselamatan ritual ngadiukkeun pare yang harus dipenuhi, yaitu hadirnya sepasang suami-isteri sebagai pelaku utama dan sepasang padi indung huma dan sepasang padi indung sawah sebagai materi neteupkeun yang menurut istilah Kusdiwanggo \& Sumardjo (2016) sakuren ngadiukkeun.

\section{(3) Kedaulatan Pangan}

Ketika di tempat lain harga bahan pangan naik karena inflasi, masyarakat adat Kasepuhan Ciptagelar dan Sinar Rresmi stabil dengan kemandirian pangan yang dimilikinya. Kemandirian pangan petani adat di Lereng Gunung Halimun ini memukau warga dunia. Uwa Ugis Suganda Amas warga masyarkat adat Cisolok, Sukabumi menjadi satu-satunya petani yang tidak mengeluh tentang kegagalan panen ketika menjadi pembicara di Pameran Produk Pangan Dunia Terra Madre dan Salona Del Gusto di Italia, Oktober 2012. Saat petani dari negara lain berkeluh-kesah, Uwa Ugis memaparkan keunggulan petani di Lereng Halimun yang mampu memiliki cadangan padi hingga 20 tahun ke depan. "Uwa membawa solusi. Intinya adalah memperlakukan bumi sebagai ibu dan langit sebagai ayah," kata Uwa Ugis Herlianti (2012).

Keunikan padi lokal mampu memikat pasar lokal dan internasional. Selain rasanya yang gurih dan pulen, keunggulan beras lokal mengandung zat oksidan lima kali lebih banyak daripada beras biasa juga terbukti bisa memperbaiki sel-sel tubuh yang rusak. Melalui Javara, Herlianti (2012) mengatakan bahwa beras lokal mampu menembus pasar ekspor, seperti Swiss, Italia, Inggris, dan Belgia. Banyaknya permintaan beras lokal belum terpenuhi karena keterbatasan stok pangan di tanah air. Masyarakat adat seperti yang terdapat di Lereng Gunung Salak yang telah berhasil melestarikan padi lokal sesuai aturan adat terlarang memperjualbelikan beras. Oleh karena itu, dapat dipahami jika konsumen tidak mudah memperoleh beras lokal. Jika ada pun, konsumen harus membayar dengan harga cukup mahal. Tingginya harga beli beras lokal diprediksi sebagai imbalan petani yang telah menjaga keseimbangan lingkungan.

Oleh karena itu, untuk memenuhi kebutuhan pasar tidak hanya masyarakat adat, tetapi pada saat ini petani biasa pun turut mengejar kemajuan ekonomi, dengan kreatif kembali tertarik menanam padi lokal karena jalur khusus menuju pasar mulai terbuka. 
Areal pertanian di Desa Gasol di kaki Gunung Gede, Cianjur, misalnya telah menguning dihiasi pertanaman padi lokal yang siap dipanen.

\section{SIMPULAN}

Berdasarkan pembahasan yang telah dilakukan beberapa hal yang perlu dicatat dalam simpulan adalah pertama, mitos Sunda sebagaimana yang telah dikemukakan perlu diketahui dan dibaca oleh masyarakat sebagai ilmu pengetahuan lokal mitigasi bencana jika benar-benar menghadapi bencana. Mitos-mitos tersebut dapat dijadikan pegangan untuk menyikapi peristiwa yang terjadi dan yang akan terjadi. Dengan memahami dan mengetahui mitos-mitos tersebut tanggapan masyarakat terhadap masalah bencana, penanggulangan, dan pencegahannya menjadi lebih baik

Demikian pula dengan mitos-mitos yang berkaitan dengan penanaman padi sangat penting diketahui oleh petani-petani yang hidup di luar masyarakat adat yang masih mengamalkan nilai-nilai leluhur mereka. untuk memperoleh keselamatan dan keberlanjutan hidup segala sesuatunya harus diupayakan dan dijadikan prasyarat. Pengupayaan ritual menciptakan kemitigasian bencana dan kedaulatan pangan secara mandiri yang akhirnya memancarkan pancer, yang merupakan keselamatan hidup kasepuhan.

Intinya, pengetahuan merupakan faktor utama dan menjadi kunci untuk kesiapsiagaan mengantisipasi bencana.

\section{UCAPAN TERIMA KASIH}

Saya panjatkan rasa syukur yang dalam kepada Allah yang Mahakuasa yang telah melimpahkan rahmat dan karunia-Nya sehingga makalah "Menafsirkan Mitos sebagai Media Mitigasi Bencana" dapat terselesaikan pada waktunya.

Makalah ini tidak akan terwujud dan terselesaikan tanpa dukungan berbagai pihak. Oleh karena itu, pada kesempatan ini sudah sepatutnya saya menyampaikan ucapan terima kasih yang tulus kepada Panitia Seminar Nasional Arkeologi Tahun 2020, Balai Arkeologi Jawa Barat yang telah memberikan kesempatan kepada saya untuk mengikuti seminar secara daring/luring serta memasukkan makalah yang telah diseminarkan dalam Prosiding Balar Jabar 2021.

\section{DAFTAR PUSTAKA}

Anafiah, S. (2014). Pemanfaatan Komik Anak Sebagai Media Mitigasi Bencana. Widyaparwa, 42(2), 25-28.

Herlianti. (2012, November). Padi Melimpah Berkah Ibu Pertiwi Ingin Cetak Kemasan

Murah? Kompas.Com, 1-6.

Hermawan, I. (2012). Bangunan Rumah Teleskop di Kompleks Observatorium Bosscha. Purbawidya, 1(N0. 1/Tahun 2012), 125--140. 
Indrajaya, D. W. (2020). Tradisi Lisan Smong Selamatkan Orang Simeulue dari Tsunami. 1--5 hlm.

Kusdiwanggo, S., \& Sumardjo, J. (2016). Sakuren: Konsep Spasial Sebagai Prasyarat Keselamatan Masyarakat Keselamatan Masyarakat Budaya Padi di Kasepuhan Ciptagelar. Panggung, 26(3), 309-322. https://doi.org/10.26742/panggung.v26i3.194

Mahayana, M. (2007). Ekstrinsikalitas sastra Indonesia (1st ed.). Raja Grafindo Persada.

Peraturan Menteri Dalam Negeri (2006). Peraturan Menteri Dalam Negeri Tentang Pedoman Umum Mitigasi Bencana. In www. gitews.org.

Pudentia, M. (2016). Tradisi Lisan Terancam Zaman. Media Indonesia, October 2016, 2-4.

Pudentia, M. (2019). Metode Kajian Tradisi Lisan. Yayasan Obor.

Ruthven. (1997). Myth: The Critical Idioms. Methuen \& Co.Ltd.

Sumarjo, J. (2009). Sastra dan Pemberadaban di Indonesia. July.

Supriatin, Y. M. (2010). Pembangunan Waduk Jatigede Dan Mitos-Mitosnya Dalam

Sastra Lisan Sunda. Jurnal Sosioteknologi, 9(20), 875-882.

Vansina, J. (1985). Oral Tradition as History. James Currey Publishers.

Wijanarti, T. (2019). Masyarakat Dayak Dan Alam: Sebuah Pembacaan Ekokritik Sastra Terhadap Cerita Pendek "Menari Di Puncak Beringin"” Karya Budi Dayak Kurniawan. UNDAS: Jurnal Hasil Penelitian Bahasa Dan Sastra, 15(2), 135. https://doi.org/10.26499/und.v15i2.1747

Zaidan, A. R. (1997). Mitologi Jawa dalam puisi Indonesia modern , 1950-1970. Pusat Bahasa $<$ Kementerian Pendidikan dan Kebudayaan.

\section{HASIL DISKUSI}

\section{Pertanyaan}

1. Muhamad Alnoza (Universitas Indonesia)

Terkait dengan mitologi Dewi Sri, padi disimbolkan sebagai Ibu, apakah sosok Ibu bisa dipandang sebagai padi? Apakah hal tersebut akan berdampak pada orang-orang dalam hal memperlakukan perempuan?

2. Nanang Saptono (Balai Arkeologi Jawa Barat)

Adakalanya mitos tidak berlaku untuk kalangan tertentu. Bentuk mitos seperti apa yang bermanfaat sebagai media mitigasi bencana? Apakah ada kriteria pada stuktur atau lapisan masyarakat yang percaya/kuat terhadap mitos sehingga bisa menjadi mitigasi?

\section{Jawaban}

1. Sudah dikemukakan tadi bahwa masyarakat kasepuhan memperlakukan padi sebagaimana mereka memperlakukan Ibu dan karakteristik seorang (perempuan). Misalnya, seorang Ibu mengandung dalam satu tahun hanya sekali. Masyarakat 
kasepuhan dalam menanam padi dalam satu tahun hanya satu kali sebagaimana seorang Ibu yang mengandung hanya satu kali dalam satu tahun. Demikian pula dalam merawat pertumbuhan padi, masyarakat kasepuhan memperlakukan padi sama dengan memperlakukan terhadap perempuan yang sedang mengandung. Padi juga mempunyai ruang khusus bagi masyarakat kasepuhan, biasa disebut goah yang hanya dapat dimasuki oleh perempuan.

Bapak jangan membalikkan: padi dimetaforkan sebagai Ibu jadi Ibu bisa dipandang sebagai padi. Itu dua hal yang berbeda. Jika Ibu dipandang sebagai padi itu artinya Ibu disamakan dengan padi. Bukan itu maksudnya.

2. Saya setuju dengan pernyataan Bapak bahwa mungkin saja ada masyarakat yang tidak percaya pada mitos karena dianggapnya mitos hanyalah cerita fiktif . Namun, justru dari mitos-mitos tersebut atau dari cerita fiktif itu terkandung berbagai nasihat, pesan moral, dan hal-hal yang terkait baik-buruk. Kita, sebagai pembaca sebaiknya mengambil manfaat pada mitos yang dipandang baik, seperti masyarakat Simeulue yang mendapat ilmu terakait tsunami dari smong. Terkait kriteria mitos seperti apa yang dapat digunakan sebagai mitigasi? Tentu saja hal pertama yang harus diketahui adalah kita harus tahu dulu apa isi mitos tersebut. Jika mitos-mitos tersebut mengandung mitigasi bencana ya mitos itulah yang yangg jadi pilihan kita. Terima kasih. 